УДК 378

\title{
СОВРЕМЕННОЕ ОБУЧЕНИЕ: ЭЛЕКТРОННОЕ, СМЕШАННОЕ ОБУЧЕНИЕ НА ПРИМЕРЕ ДИСЦИПЛИНЫ «ФИНАНСОВАЯ МАТЕМАТИКА»
}

\author{
Агапова Е.Г., Кононович П.А.
}

Для того чтобы стать моделью «Цифрового университета», наряду с информационной системой управления университетом, ключевыми компетенциями циифровой экономики и управлением учебным прочессом на базе индивидуальной образовательной траектории требуется разрабатьвать и поддерживать онлайн-обучение. Если относительно гуманитарных дисциплин вопросов создания онлайнкурсов не имеется, то с точки зрения точных дисциилин, а такюе технических направлений подготовки этот вопрос является спорным: как и что можно предложить слушателям? Авторы статьи на примере электронно-учебного курса «Финансовая математика» рассматривают возможность смешанного обучения на кафедре «Прикладная математика» Тихоокеанского государственного университета (ТОГУ, г. Хабаровск).

Ключевые слова: онлайн-курсы; математические дисциплины; электронно-учебный курс; смешанное образование; платформа Moоdle.

\section{MODERN LEARNING: \\ ELECTRONIC, MIXED LEARNING ON THE EXAMPLE OF THE DISCIPLINE "FINANCIAL MATHEMATICS"}

\section{Agapova E.G., Kononovich P.A.}

In order to become a model of the Digital University, along with the information management system of the university, the key competencies of the digital economy and the management of the educational process on 
the basis of an individual educational path, it is necessary to develop and maintain online education. If there are no questions regarding the creation of online courses regarding the humanities, then from the point of view of the exact disciplines and the technical areas of preparation, this question is debatable: how and what can students offer? The authors of the article, using the example of the e-learning course "Financial Mathematics", are considering the possibility of blended learning at the Department of Applied Mathematics of the Pacific State University (PNU, Khabarovsk).

Keywords: online courses; mathematical disciplines; e-learning course; blended education; Moodle platform.

Современные цифровые технологии дают возможность университетам всего мира повышать доступность и качество образования за счет взаимодействия и внедрения учебных программ. В настоящее время наблюдается быстрая адаптация онлайн-обучения, которое выражается в виде развития смешанных форм обучения (blended learning) и в активном развитии онлайн-курсов MOOC (Massive on-line open course). Появление растущего онлайн-сегмента образовательных услуг может полностью изменить ландшафт данной сферы: кроме ежегодного удвоения численности предлагаемых курсов и количества слушателей прогнозируемая консолидированная выручка рынка MOОС увеличится более чем в пять раз к 2020 г., по некоторым оценкам.

«Нет никаких гарантий, что полученная в сети информация является достоверной и безопасной. Существует реальный дефицит качественного образовательного контента. Поэтому нужно создать специальные ресурсы, которые могут быть протестированы специалистами и встроены в университетские программы», - сказал А.Д. Медведев. По его словам, такие ресурсы уже есть, но их немного. «Ими будут пользоваться студенты и преподаватели не только в нашей стране, но и за рубежом»,- добавил премьер. По его словам, на решение этой задачи нацелено четвертое направление этого национального проекта - современная цифровая образовательная среда.

В современном цифровом мире можно донести математические термины, математические формулировки и математические мето- 
ды в интерактивном виде [1, с. 6-8]. В настоящее время все больше студентов обращаются к онлайн-курсам по математическим дисциплинам [2, с. 4-5]. Особое внимание уделяется проверке домашних заданий, тестов, курсовых работ [3, с. 244], [4, с. 15].

Для обучающихся по направлению «Прикладная математика» на платформе Moodle в цифровой обучающей среде ТОГУ наряду с другими курсами создан электронно-учебный курс «Финансовая математика». Данный курс может помочь студентам экономических направлений подготовки, которые изучают эту дисциплину. Платформой курса является платформа Moodle. Известно, что эта платформа является доступной в использовании, имеет высокий уровень безопасности.

Итак, электронно-учебный курс «Финансовая математика» начинается с описания дисциплины, содержит четыре раздела: логика финансовых расчетов; вычисление по простым и сложным процентам; финансовая эквивалентность обязательств; оценка эффективности финансовых операций; финансовые ренты. Каждый раздел содержит: лекцию, задания для самоконтроля или задачи, тест или эссе, чат-обсуждение или вопросы и предложения по теме раздела. Промежуточным итогом данной дисциплины является «зачет».

Итоги изучения дисциплины «Финансовая математика» студентами учебной группы ММИ(аб)-51 ТОГУ показали 100\% успеваемости. При этом студенты отметили, что наличие электронно-учебных курсов позволяют быть мобильными, обучающие не привязаны к аудитории, и у них есть возможность строить карьеру и параллельно эффективно учиться. Студентам, у которых есть проблемы со здоровьем, это тоже очень удобно: они могут минимизировать количество посещений и не терять в эффективности обучения. Если студенты пропустили лекции, у них тоже есть возможность не отставать от всего потока, а в удобное время и в удобном режиме наверстать пропущенное».

Таким образом, разрабатывая электронно-учебные курсы, осуществляется онлайн-поддержка образовательного процесса ТОГУ, а это приближает наш университет к модели «Цифрового университета». 


\section{Список литературы}

1. Агапова Е.Г., Попова Т.М., Лян Ю.Г. Формы интерактивных методов обучения математическим дисциплинам // Russian Journal of Education and Psychology. 2019. T. 10. № 3. C. 6-10.

2. Агапова Е.Г., Попова Т.М., Лян Ю.Г. Онлайн-курсы по математическим дисциплинам // International Journal of Advanced Studies in Computer Engineering. 2019. № 1. С. 4-7.

3. Козлов Д.Е., Попова Т.М. Разработка приложения «Курсовые работы» на платформе 1С // Ученые заметки ТОГУ. 2017. Т. 8. № 3. C. 243-248.

4. Козлов Д.Е., Попова Т.М. Автоматизация проверки уникальности в информационной системе «Курсовые работы» // Ученые заметки ТОГУ. 2019. Т. 10. № 1. С. 14-19.

\section{References}

1. Agapova E.G., Popova T.M., Lyan Yu.G. Formy interaktivnyh metodov obucheniya matematicheskim disciplinam [Forms of interactive methods of teaching mathematical disciplines]. Russian Journal of Education and Psychology. 2019. V. 10. № 3, pp. 6-10.

2. Agapova E.G., Popova T.M., Lyan Yu.G. Onlajn-kursy po matematicheskim disciplinam [Online Courses in Mathematics]. International Journal of Advanced Studies in Computer Engineering. 2019. № 1, pp. 4-7.

3. Kozlov D.E., Popova T.M. Razrabotka prilozheniya «Kursovye raboty» na platforme 1S [Development of the application "Coursework" on the 1C platform]. Uchenye zametki TOGU. 2017. V. 8. № 3, pp. 243-248.

4. Kozlov D.E., Popova T.M. Avtomatizaciya proverki unikal'nosti v informacionnoj sisteme "Kursovye raboty» [Automation of uniqueness verification in the information system "Coursework"]. Uchenye zametki TOGU. 2019. V. 10. № 1, pp. 14-19.

\section{ДАННЫЕ ОБ АВТОРАХ}

Агапова Елена Григорьевна, доцент, кандидат физико-математических наук, доцент Тихоокеанский государственный университет 
ул. Тихоокеанская, 136, г. Хабаровск, 680035, Российская Федерачия

000614@pnu.edu.ru

Кононович Павел Алексеевич, магистрант

Тихоокеанский государственный университет

ул. Тихоокеанская, 136, г. Хабаровск, 680035, Российская Федерачия

2015103585@pnu.edu.ru

\section{DATA ABOUT THE AUTHORS}

Agapova Elena Grigoryevna, associate professor, candidate of physical and mathematical sciences, associate professor Pacific National University 136, Tikhookeanskaya Str., Khabarovsk, 680035, Russian Federation 000614@pnu.edu.ru

Kononovich Pavel Alekseevich, undergraduate

Pacific National University

136, Tikhookeanskaya Str., Khabarovsk, 680035, Russian Federation 2015103585@pnu.edu.ru 